\title{
Pragmatics and Iconicity as Factors Explaining the Paradox of Quantified Proper Names
}

\section{WILLY VAN LANGENDONCK}

The aim of this paper is to interpret some partly known paradoxical phenomena concerning proper names (PNs) and number in light of the central paradox which characterizes the essence of PNs. This fundamental paradox resides in the semantic structure of the PN. In the past, a number of contradictory statements have been put forward. On the one hand, it has been posited that PNs are meaningless. Others have argued that the PN is the word-class with the largest semantic content. $^{1}$ I would like to reconcile these antitheses in formulating them as the semantic paradox of the PN. Indeed, the two positions are only seemingly contradictory. In fact, the whole confusion derives from the misunderstandings about the definition of the term "meaning." 1. To escape from this chaos, it is necessary to distinguish between different kinds of meaning. ${ }^{2}$ Firstly, there is the big dichotomy between the strictly logico-semantic or conceptual meaning and the pragmatic or associative meaning. The conceptual meaning is said to be the primary, more or less objective meaning inherent to a linguistic element. As for words, one can further distinguish between lexical and grammatical meaning, as is well-known.

The pragmatic or associative meaning aspects pertain to the more or less subjective, secondary connotations that words may display. These connotations are rather vague and unstable; i.e., they are not inherent to the linguistic element as such, but are associated with them in some roundabout way. They differ from speaker to speaker, though they may be shared by the whole speech community as well. The language user may, e.g., assign connotations to a linguistic entity which are derived from properties of its referent. For instance, a word like bachelor, in its semantic reading "unmarried man," will be assigned connotations via its referents, varying from "solitary,

\footnotetext{
1 See also Van Langendonck (1981).

2 See especially Leech (1974).
} 
self-contained man, poor fellow" to "merry-maker, reveller," etc. depending on the views the language user takes. The pragmatic associations can also be taken from the meaning of a homophonous element. A good example is the Dutch expression de Engelse Groetenis, which means "the Angel's Salutation" (Ave Maria), but could also mean "the English Salutation." This homophony finally led to the extinction of the expression, obviously because of the inconvenient connotation coming from the homonym.

2. It seems plausible to reconsider the meaning problems regarding PNs in light of this variety of kinds of meaning. We will mainly concentrate on so-called quantification of PNs.

2.1 The question whether the PN contains any conceptual meaning has been treated by a host of investigators, also by the present author. $^{3}$ Suffice it to recall here the thesis that PNs are devoid of lexical meaning, but that they do contain some peripheral grammatical meanings. Typical of these grammatical meanings is that they appear to be fixed. Though it is denied by certain theoreticians, it is usually argued that PNs are inherently definite and singular. They cannot have the opposite values of these features. ${ }^{4}$ In any case, it cannot be denied that definiteness and singularity are stereotypical characteristics of PNs. A sentence like Johns are here sounds extremely odd. When used without an article, PNs behave syntactically like definite noun phrases. The following test is a proof of this. In Van Langendonck(1979) it is observed that definite, but not indefinite NPs can occur as an "afterthought," i.e., in right dislocation, as it is called in TGG. PNs behave just like definite NPs in this respect. Compare:

(1) a. He is very rich, the oil-magnate. /DEF/

b. He is very rich, Mr. Rockefeller./PROP/

c. * He is very rich, a (certain) oil-magnate./INDEF/

The contention that PNs are singular does not imply that they are a kind of mass nouns, as is sometimes thought. Though PNs, at least personal and country and city names, lack the article, they act like countable singular nouns, which can display the articls $a(n)$. It should be pointed out that PNs too can display this article, viz. in the peculiar construction that idiot of a John. This seems to contradict the above claim that PNs are inherently definite. However, in this pattern, the article $a(n)$ merely indicates countable singularity. In fact, it looks as if the determiners of the nominal construction are

\footnotetext{
3 Van Langendonck (1981).
}

${ }^{4}$ For a recent attack on these assumptions see Leys (1979). 
reversed: we are inclined to paraphrase it as "that John, who is an idiot." At any rate, the sequence a John in the above pattern is different from the ones we will turn to later on, e.g. in I know a John who lives next door, though it should be emphasized that in the like examples the same countable singularity is observed.

The counterexamples to the thesis that PNs are inherently singular are well-known. They are of two kinds.

There are a few examples of PNs which are inherently plural in form, e.g. the Pyrenees, the Philippines, etc. However, semantically, these are cases of a collective plurality, i.e. a plurality which is viewed as a unity, a singularity. The impossibility of a distributive or appellative plurality in these pluralia tantum is evidenced by the impossibility of such quantified expressions as *(the) many Pyrenees; *a number of Philippines, etc. It is paradoxical, then, that formally singular PNs like John or London can be pluralized and quantified, e.g. I know a lot of Johns; Is there more than one London? etc. It will be argued here that the latter uses of PNs are motivated pragmatically. They are a reflection of the pragmatic values assigned to number and determination when used in PNs. In such uses PNs become derived appellatives. Let us adduce a few arguments for this distinction.

i) From a logical viewpoint, it is impossible to quantify over constants; therefore, one cannot quantify over PNs and demonstratives, at least when it is agreed that these categories are constants, i.e. that they do not contain any predicative content. ${ }^{\mathbf{5}}$

ii) PNs in their primary use cannot refer back anaphorically to appellative expressions, whether derived from PNs or not; compare the anaphoric capacity of personal pronouns and definite appellative NPs with the non-anaphoric capacity of (real) PNs:

(2) During the war I knew a certain officer (or a certain Peterson). One can continue with the sequels a and $b$ :

a. This officer was a hell of a man.

b. This Peterson was a hell of a man.

But it is very awkward to go on with

c. Peterson was a hell of a man.

This awkwardness comes from the fact that Peterson, as a real PN, cannot refer anaphorically to a certain officer or a certain Peterson, while the appellative NPs this officer and this Peterson can.

iii. When referents of PNs are to be added, the only way to use

5 For the semantic and formal similarity between PNs and demonstratives, see Van Langendonck. (1981). 
the PNs while keeping them intact is to conjoin them. Morphological pluralization is reserved for common nouns. It is even possible to conjoin homonymous PNs, whereas this is excluded with common nouns; compare:

(3) a. Johnson and Peterson.

b. Johnson and Johnson.

c. * The boy and the boy.

d. The boys.

I would like to explain this fact as an iconic phenomenon. The import assigned to iconicity in language is steadly growing. ${ }^{6}$ Iconicity is present when the sign mirrors properties of its referent. In the lexicon, imagic iconicity is found in onomatopoeias (e.g. crack, cuckoo). In the grammar, one can speak of diagrammatic iconicity. It is present when some formal pattern reflects a pattern in reality in a diagrammatic, i.e. a schematic way. For instance, semantic and referential complexity is often mirrored by formal complexity (the phenomenon of markedness). A common example is number: in a lot of languages, the semantically simpler singular is rendered by zero form, while the complex notion of plural is expressed by some overt form (compare English: boy vs. boy-s). The above formal opposition between PNs and appellatives seems to be iconic too. The pluralization of appellatives by means of a single (albeit suffixed) lexeme mirrors the fact that the pluralized appellative refers to members of the same class or kind. The impossibility of pluralization or quantification with genuine PNs is an icon of the fact that they cannot refer to members of a class as members. The adding of referents by means of syntactic conjunction is also iconic. Conjoining mirrors the fact that the conjuncts refer to entities that are not necessarily members of the same class, e.g. there is no single pluralized word to represent the adding of, say, a cow and a goat; the only possibility to add them is to conjoin them, as I have just done. Likewise, the only possibility to represent the adding of referents of PNs, even of homonymous PNs, is to conjoin the PNs, because these PNs do not necessarily refer to entities of the same class (though often they do).

The question arises now what the function is of pluralized forms of PNs (Johns, Londons etc.).

2.2 I will propose the thesis that the different occurrences of pluralized PN-forms reflect different pragmatic meanings. However, it should be noticed that formal pluralization of PNs does not neces-

6 See Haiman (1980); Posner (1980); Panhuis (1981). 
sarily result in appellativization. But, whether they are appellatives or not, the pragmatic values of these plural forms do not normally occur with ordinary appellatives. This is to be expected, since in the latter, the plural morpheme fulfills the function of quantification in the first place.

Four cases of pragmatic use of pluralized PN-forms will be distinguished; they derive respectively from cultural, emotive, social-stylistic connotations, and from an association with homophonous words. 1) The first factor is constituted by cultural connotations. One can associate a referent with his family, or with his earlier manifestations of himself, or metaphorically with a different, famous, referent.

i) When certain referents belong to the same family or clan, one can use the plural of the (collective) PN-form, e.g. the Carpenters, or the Kennedys. These formations are analyzable as the persons of the Carpenter family and the persons of the Kennedy clan respectively. These paraphrases reflect a semantically complex structure: a real PN embedded in an appellative construction. Of course, we do not encounter this type of plural in common nouns.

ii). Another kind of cultural connotation results in splitting up the referent in subindividuals or submanifestations. ${ }^{7}$ This splitting is found in such statements as:

(4) a. There are two Romes: classical Rome and modern Rome.

b. We can distinguish two Napoleons: the Napoleon of Waterloo was no longer the same as the Napoleon of Austerlitz. The like patterns are uncommon with appellatives. ${ }^{8}$ We can paraphrase them as follows: two Romes = two submanifestations of Rome; two Napoleons $=$ two subindividuals of Napoleon. The PN is again embedded semantically in an appellative construction.

iii) In the third kind of cultural connotation, the referent is compared to some famous congener. The result is a metaphor:

(5) a. This general is not another Napoleon.

b. There are not so many Einsteins in our world.

This kind of metaphor is rarely found with common nouns. ${ }^{9}$ The relevant constructions in (5) can be paraphrased as another $X$ like $Y$

7 For this notion, see Dahl (1975).

8 They do occur with monoreferential expressions like the sun; compare: Yesterday's sun is not today's!

9 Exceptions may again be encountered with monoreferential expressions, e.g. The moon will never become anotber sun. 
and many $X$ 's like $Y$ respectively. Here too, the semantic structure is a real $\mathrm{PN}$ embedded in an appellative pattern.

2) Another kind of pragmatic meaning is constituted by emotive connotations. These are the result of the personal feelings that a speaker may nurse with respect to a referent and which may be transferred to the name. Diminutive and augmentative formations are typical here. Even the plural form of real PNs is sometimes used to express emotive connotations. A nice example comes from Mexican Spanish: ${ }^{10}$

(6) Qué lindos son los Manuelitos!

(How sweet is Manuel!)

The plural form of the first name Manuel in (6) has a purely diminutive force, just like the accompanying article los and the diminutive suffix -ito. The plural again seems to be applied metaphorically: it looks as though the speaker wants to engender the multiplication of the amiable properties of the referent. With common nouns, this pluralization process is totally excluded.

3) The third pragmatic factor can be accommodated under the heading "social-stylistic" associations, i.e. those that linguistic elements receive from the (social) situation. For instance, in Dutch, number agreement of the verb with an inherently plural PN as subject is unstable:

(7) De Pyreneeën is/zijn een gebergte.

(The Pyrenees is/are a range of mountains.)

For most native speakers, plural agreement sounds more natural, i.e. less formal than singular agreement. The same variation is, however, possible with appellative pluralia tantum like hersenen "brain(s)." 11

4) The last pragmatic factor to be discussed is the influence of homophony on pluralization and quantification of PN-forms. When, e.g., more than one person is called John, constructions of the following (rather common) type may result:

(8) a. There are a host of Johns.

b. I know more than one John.

In (8), the word John will be best paraphrased as person with the name "John." This pattern contains an appellative head person and a

10 Svennung (1958:405).

11 Compare the sentence: De bersenen is/zijn een verzameling kronkels (The brain(s) is/are a set of coils). 
real PN John, which in this case refers not to a person, but to itself: it is actually an autonym. As a matter of fact, an autonym is a PN as well, ${ }^{12}$ so the whole construction is parallel to the above ones: the Carpenters, two Romes, and another Napoleon. Furthermore, the construction with PNs as autonyms is not applicable to common nouns. Although the word bank, exactly as the PN John, is ambiguous, one cannot speak of (the) two banks when one means that there exist two kinds of banks (e.g., ridges and financial institutions); in that case, the paraphrase with the term "kind" has to be used, as I have just done. On the other hand, this paraphrase does not obtain in the case of homonymous PNs: a host of Johns is not equivalent to a host of kinds of John, but rather to a host of individuals with the name "John." This illustrates once more that PNs refer to individuals, while appellatives indicate kinds.

3. The above behavior of PNs with regard to number mirrors the fundamental paradox outlined in the introduction. The absense of lexical, predicative meaning in PNs excludes the application of the number opposition singular vs. plural as in the instance of common nouns, where it is possible to add up or oppose the members of a class or kind. Where number performs a conceptual (grammatical) function in PNs, it can only serve to indicate singularity or collectivity. On the other hand, this reduction on the conceptual side is compensated by an extention of the functions of number for the manifestation of various pragmatic connotations in a way unknown in common nouns. Where an appellative derivation of a PN is concerned, this construction (e.g. the Carpenters, two Romes, another Napoleon, a host of Johns) can be analyzed semantically as an embedding of a real PN in an appellative head.

The above observations about the semantic (conceptual) and pragmatic functions in PNs or appellative NPs derived from PNs are in accordance with the more general thesis that there is, in principle, a distinction to be made between real PNs, which bear no lexical meaning and common nouns, which contain predicates constituting classes or kinds. The distinction is further corroborated by the phenomena concerning the iconicity of the expression of number in PNs and common nouns, in that they stress the difference between the two categories.

Last but not least, there have been recent findings which adduce

12 See Van Langendonck (1981). 
extralinguistic, i.e. psycholinguistic evidence for the above dichotomy. ${ }^{13}$

Katholieke Universiteit Leuven (Belgium)

References

DAHL, Ö. (1975). Individuals, subindividuals, and manifestations. (Logical Grammar Reports 15). Univ. of Göteborg, Dept. of Ling.

HAIMAN, J. (1980). The iconicity of Grammar. Language 56:515-541.

LEECH, G. (1974). Semantics. (Penguin Books.) Harmondsworth.

LEYS, O. (1979). Was ist ein Eigenname? Ein pragmatisch orientierter Standpunkt. Leuvense Bijdragen 68:61-86.

PANHUIS, D. (1981). The arbitrariness of the lingual sign as a symptom of linguistic alienation. Studies in Language 5:343-360.

POSNER, R. (1980). Ikonismus in der Syntax. Zeitschrift fur semiotik 2:57-82.

STACHOWIAK, Fr. J. (1980). Zur Referenz und Bedeutung von Eigennamen aus psycholinguistischer Sicht. In: Seiler, H., ed. Apprehension. Das sprachliche Erfassen von Gegenstanden. II.Teil.

SVENNUNG, J. (1958). Anredeformen: Vergleichende Forschungen zur indirekten Anrede in der dritten Person und zum Nominativ für den Vokativ. (Acta Soc. Litt. Hum. Reg. Upsal.42). Uppsala \& Wiesbaden.

VAN LANGENDONCK, (1979). Definiteness as an unmarked category. Linguistiche Berichte 63:33-55.

VAN LANGENDONCK, W. (1981). On the theory of proper names. In: Proceedings of 13th International Congress of Onomastic Sciences (Cracow 1978), ed. by K. Rymut, Vol. I: 63-78. Wroclaw etc.: Ossolineum.

${ }^{13}$ See Stachowiak (1980). 